patient relief ; but, fearing an interruption to the cure, and the man rolunteering to continue the pressure, I determined to persevere until the morrow.

The following morning, I was agreeably surprised at being told that three hours after seeing him on the previous day, when loosening the compressor for readjustment, he found that the tumour did not pulsate, and that it had not done 80 since. Examination proved this to be correct; the tumour felt solid, free from impulse, and there was no bruit audible. The pressure was lightly applied during the next twenty-four hours, and then (January 15th) entirely withdrawn.

In the sixteen days during which the pressure was used, he took preparations of opium equivalent to one drachm of the crude drug; that is, rather less than four grains per diem. During the next fortnight, he remained quietly in bed; the oedema diminished rery slowly. He was then allowed to get up, and gradually began to move, and stand on the limb. The swelling in the popliteal space and general thickening at first prevented much bending of the knee; friction was used, and the improvement went on without interruption; and in the early part of April, he resumed his work as a labourer.

I saw him a few days ago at work; the affected thigh is still an inch larger than the other; the cutaneous veins are fuller than usual; and there is a puffiness at the ankle at night. I could not discover any of the arteries by which the leg is receiving its supply of blood. The knee can be bent to almost the natural extent; and the man is able to do a fair day's work, with only a little uneasiness about the foot and knee at night.

REMARKS. In considering the treatment to be adopted for this case, three plans presented themselves; 1st, laying open the tumour, removing the congula, dissecting out the artery, and ligaturing it above and below the wound in it: 2nd, ligature in the usual Hunterian method; and 3rd, pressure in the mode recently so often used for idiopathic aneurism.

The difficulties attending each plan would of course he greatly increased, in consequence of the man being five miles from any surgeon, in a small cottage, without any trained nurse. Of the first plan, Professor Erichsen says, it is "an operation easy in description, but most difficult and tedious in practice"; and it appeared to me in this instance to be so fraught with difficulty and danger, that I should have resorted to it unwillingly.

The following passage from Erichsen's Surgery, p. 514, appeared thoroughly to describe my patient's case, and to indicate the treatment:- "In some instances of popliteal aneurism," he says, "the aneurism has not from the first been very distinctly circumscribed. It has followed the infliction of some mechanical injury, and in the course of a week or two has acquired a considerable size, without definite or distinct limitation, being solid or but little compressible. Such a case as this can scarcely be considered a diffused aneurism; but yet if by circumscribed we mean that the blood is contained in a defined cyst with walls, it scarcely complies with such a definition, the fluid blood being rather prevented escaping widely by a temporary barrier of coagula entangled in the loose cellular tissues of the part, and the ressel being ruptured to a considerable extent or completely torn across. Here we are certainly justified in having recourse to ligature with good prospect of success."

But my conviction was, that carefully conducted pressure would insure a filling up of the aneurism as effectually as a ligature on the femoral would; and the danger to $\mathrm{my}$ patient under the existing circumstances would be very much less. I therefore adopted this mode; and the result shows that the decision was a sound one, and also furnishes another illustration of the great advantage accruing to patient and surgeon from this modern addition to our surgical appliances.

Whilst this case was being treated, I was not aware that this traumatic variety of aneurism had been at any time treated by compression in the manner I have described; but from a note with which Dr. Bellingham, of Dublin, has recently favoured me, I learn that there have been some analogous cases so treated with success; though this is, I believe, the first one involving the popliteal artery.

\section{ON THE DISEASES OF THE EAR PREVAILING} IN LANCASHIRE AND CHESHIRE.

By W. C. Wiumayson, Esq., M.R.C.S.Fing., F.R.S., Surgeon to the Manchester Institution for Diseases of the Ear; Professor of Anatomy and Physiology in Owen's College, Manchester.

[Read before the Lancashire and Chcshire Branch, June 25th, 1550.]

I FEen that some apology is due to the members of this Branch for presuming to bring before them the results of inquiries that have only been in progress during a period of twelve months. But having been invited to contribute something to the proceedings of this meeting, I naturally turned for my material to those investigations which I had been pursuing quietly, but assiduously, during the past year, as presenting more of novelty than anything else that I could bring forward.

It must be remembered that such inquiries are not foreign to the antecedent studies of any well educated surgeon ; consisting only in the application of well known principles of surgical and pathological science to an individual organ: consequently, any member of the profession whose preceding life has been devoted to careful scientific research may fairly expect to obtain trustworthy results in a shorter period than when the subject is wholly new, or the habit of original research has yet to be established. At the same time, I only presume to bring my conclusions before you as the first fruits of an inquiry, which I hope to continue, if life be spared, through many future years; during which period each year will necessarily add to the value of such conclusions consequent upon increased experience and familiarity with my subject.

There are probably no diseases to which medical men generally have paid so little attention as those affecting the organ of hearing. The several causes of this neglect are easily found. The comparative rarity of the cases limits the number coming under the eye of each practitioner. Hence that ready apprehension of their various aspects which can only result from constant familiarity with them can scarcely be attained, unless the opportunity is afforded of seeing them in larger numbers than usually falls to the lot of medical men. This obstacle to the study of these diseases is rendered additionally formidable by their unusual obscurity, owing to the complex structure and inaccessible position of the organ they attack. Numerous cases present themselves which must be obscure, even to the mosi experienced. Empiricism may profess to raise the reil which hides their pathology, and to read the unreadable; but to the scientific explorer, they are, as yet, like Sinaitic inscriptions on eastern rocks, having a history to reveal, but needing some Rosetta stone which would afford the clue to their interpretation.

A third obstacle to the study of these cases arises from the fact, that few of the instruments usually fo:nd in the surgeon's cabinet or pocket-case, are of any use to the aural surgeon. He requires a special array of illuminators, specula, otoscopes, and forceps.

Lastly, the idea that the practice of this branch of the profession involved little more than quackery, has further deterred men from its pursuit; it being supposed that nothing decidedly beneficial could be accomplished with the bulk of the cases. But why this imputation should rest against aural rather than against ophthalmic surgery, I have yet to learn. It originates in a baseless prejudice, if not resorted to in palliation of ignorance.

Three modes of treatment are usually adopted in these cases by the majority of medical practitioners. A patient 
prevents himealf at the medioal man's recidence, complaining of deafiness. The oar is learnodly looked at, but ithout such simple auxiliaries, eren, as the speculum or the otoscope, so eseential to the revelation of what is going on within the organ. This satisfactory examination is succeeded by the indiscriminate use of the syringe; and lucky is the man whose employment of it is followed by the liberation of some indurated wax, and the relief of his patient. His look now becomes even more learnedly professional than before, whilst inwoardly he is thanking his stars at the luckiness of the hit. But how if he misses, and no wax presents iteelf? Why, he has recourse to the second popular curative plan. Onders a little oil or glycerine to be dropped into the ears, and hurries his patient out of the house as speedily as he can, to escape awhward questions respecting the deaf man's state and prcspects. I have not been without personal experience of this sort of thing in the earlier days of my professional life.

But in another class of cases a third mode of professional treatment prevails. An anxious mother brings her pet boy, who has for some time had "a running at the ears". The let-alone system is now acted upon. The danger of meddling with an organ so delicate, and in such close contiguity to the brain, is now suggested, and the comforting assurance given that the lad will outgrow the disease. Outgrow what? A process of destructive ulceration, which is successively assailing one tissue after another, until incurable deafness will one day ensue! Where is the danger of interference? The connexion existing between the brain and the ear is much less direct than that between the brain and the eye! Yet who hesitates to have recourse to ophthalmic surgery, when active inflammation attacks the eye, or when chronic disease renders necessary the couching needle or the cornea knife? Both these notions are unworthy of a learned profession, and should be abandoned.

But whilst thus condemning a prevalent loose style of practice, I would guard against assuming too much for the scientific aural surgeon. I have at present no faith in the extremely exact diagnoses of some obscure affections that we occasionally hear of. I rarely find such results attainable even when disease is patent and on a large scale; still less, when the parts are minute and the organs hidden.

In the subjoined statements, I have refrained from meddling with inquiries of the more obscure class, leaving them to some future occasion, when prolonged experience shall render my appearance before my professional brethren more justifiable than now. I have selected the more prominent features of $\mathbf{1 5 5}$ indiscriminate cases that have come under my care during the last nine months-cases drawn from nearly every class of the community around us; and, consequently, though their number may be comparatively small, calculated to afford a fair idea of the nature of the aural diseases prevailing in the district.

The following table contains a numerical record of the proportions in which the more important symptoms existed in these cases:-

Disorganisation of the epithelial lining of meatus externus

Acute inflammation of ditto

Meatus swollen and narrowed

Imperforate meatus

Foreign body in ditto

Impacted cerumen

Deficient secretion, or absence of cerumen $\quad: 32$

Acute inflammation of membrana tympani : 5

Accidental perforation of ditto : : 1

Perforation of ditto from nlceration : $\quad: 10$

Destruction of ditto from ditto $\quad . \quad \quad .22$

Retraction of ditto. $\quad . \quad 28$

Dull milkiness and opacity of ditto $\quad \cdot \quad$. 51

Shining milkiness of ditto . $\quad . \quad$. 22

Purulent discharge in meatus $\quad . \quad \quad 33$

Granulations, or false polypi in ditto : 12

Exfoliation of bone from meatus : $\quad$. 1

Relazed throat : $\quad \cdot \quad$. $\quad 37$

Elongated uvula : $\quad: \quad \quad: \quad$ : 19

\begin{tabular}{|c|c|c|c|}
\hline $\begin{array}{l}\text { Enlarged tonsils } \\
\text { Obetruction of Ev } \\
\text { Nervous deafness }\end{array}$ & $\begin{array}{l}\text { stachian tnibe } \\
\text { (congenital or other }\end{array}$ & ín & $\begin{array}{r}10 \\
: \quad 9 \\
\end{array}$ \\
\hline ExctrIsG & AND PREDISPOSHNG & CAUBES. & \\
\hline Cold & - & - & \\
\hline Blow (violence) & - & $\bullet$ & . \\
\hline Measles . & • & $\bullet$ & - \\
\hline Scarlec fever & & - & - \\
\hline Foreign bodies ent & ering meatus extern & aus & \\
\hline Congenital & . & . & - \\
\hline Convulsions & . & . & $\bullet$ \\
\hline Typhus fever & - & - & \\
\hline Hooping-cough & . & - & \\
\hline Strumous diathesi & • & - & \\
\hline
\end{tabular}

In recording the probable causes of disease in these cases, it will be seen that I have only enumerated them in ninety-one out of the total number, having only done so when I had good reason for believing that I had ascertained them with something like accuracy. But I hare little hesitation in affirming that many of the remaining sixty-four cases arose from forms of catarrhal affection; the influence of the latter in originating such ailments has been shewn by most writers on aural surgery; and my own comparatively limited experience fully accords with theirs. Further, I have little doubt that in at least four-fifths of the above instances inflammatory action, of varying intensity, was the direct agent in effecting the mischief : a circumstance that teaches the importance of timely attention to such action, especially in connexion with exanthematous and other febrile diseases. For a practitioner to neglect such indications in the eye would be deemed absurd. Then why in the ear? In some of the cases recorded as originating in catarrhs, a rheumatic diathesis existed; but to a much smaller extent than the remarks of other writers had led me to expect.

It will have been observed, that in only nineteen of the above 155 cases, was hardened wax present; and even in two of these it was not the cause of the deafness; so that the conditions capable of being relieved by the indiscriminate system of syringing, already referred to, only existed in about eleven per cent. of the entire number; whilst the application of the various oils is entirely useless.

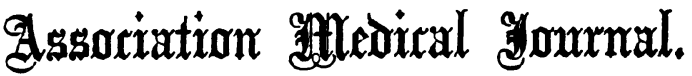

SATURDAY, JULY 12TH, 1856.

\section{THE POSTPONEMENT OF THE MEDICAL BILC.}

Ir will be seen, on reference to our parliamentary intelligence, that the Medical Bill has been dropped for the session. As the season went on, and the recommittal of this measure night after night was postponed, we feared that such would be the case. Parliament will be prorogued, it appears, on or about the 24th instant; and as the slanghter of the innocents has already commenced, we must not feel surprised that our own Bill has shared the fate of others. As for the Board of Health, we fear its own necessities have obliged it to desert us. Like a stout swimmer, at the early portion of the session it struck out into the parliamentary sea with the Vaccination Act and the Medical Bill, one on

- In some instances, it is next to imposaible to determine whether the case is one of nerrous deafness, or depenulent on disvrganisation of the deli. 